\title{
Türkiye denizlerinde GNSS reflektometre tekniği ile deniz seviyesi değişiminin araştırılması
}

\author{
Cansu Beşel ${ }^{1 *}$ iD , Emine Tanır Kayıkç $1^{1}$ (D) \\ ${ }^{1}$ Karadeniz Teknik Üniversitesi, Mühendislik Fakültesi, Harita Mühendisliği Bölümü, Trabzon, Türkiye.
}

\begin{abstract}
Öz: Küresel ve bölgesel ölçekte deniz seviyesinde meydana gelen değişimin belirlenmesi ve değişimin nedenlerinin anlaşılması iklim değişikliği çalışmalarında önemlidir. Küresel Navigasyon Uydu Sistemleri (GNSS) sinyalleri, uzaktan algılama uygulamaları için kullanılabilecek bazı ayırt edici özelliklere sahiptir. GNSS tabanlı deniz seviyesinin belirlenmesine olanak sağlayan GNSS Reflektometre (GNSS-R) tekniği yeni ve geliştirilmeye açık bir teknik olarak karşımıza çıkmaktadır. Bu çalışmada, Türkiye'nin farklı kıyılarında bulunan sabit GNSS istasyonlarının GNSS-R ile deniz seviyesi belirlenmesine katkısının araştırılması amaçlanmıştır. Bu amaçla, TUSAGA-Aktif ağında bulunan ANMU, DATC, FASA, SINP ve TEKR, IGS ağında bulunan MERS ve TÜBİTAK 1001 projesi kapsaminda tesis edilen SAME sabit GNSS istasyonlarına ait Sinyal Gürültü Oranı (Signal to Noise Ratio, SNR) verileri kullanılmıştır. SNR sinyallerinin dominant sinyal yansıma etkisi frekansı Lomb-Scargle periodogram (LSP) yöntemi ile belirlenmiştir. Yapılan çalışma sonucunda, MERS ve TEKR istasyonlarının güçlü yansıma genliklerine sahip olduğu ve anlamlı gözlemler içerdiği görülmüş olup GNSS-R ile deniz seviyesi belirlenmesine uygun istasyonlar olarak belirlenmiştir. Bu istasyonlarda hesaplanan GNSS tabanli deniz seviyesi gözlemleri istasyon yakınında bulunan mareograf gözlemleri ile karşılaştırılarak aralarında sırasıyla 0.76 ve 0.91 korelasyon bulunmuştur.
\end{abstract}

Anahtar Sözcükler: Deniz seviyesi, GNSS reflektometre, Sinyal gürültü oranı, Lomb-Scarge periodogram

\section{Investigation of sea level variations in Turkish coasts using GNSS reflectometry}

Abstract: Determination of the sea level changes and understanding the causes of changes are important in climate change studies at global and regional scales. The Global Navigation Satellite System (GNSS) signals have some characteristics that can be used for the remote sensing applications. GNSS Reflectometry (GNSS-R) technique that allows GNSS-based sea level determination is new and open to improvement. This study aims to investigate the contribution to the GNSS stations located in the different coasts of Turkey to determination of sea level by using GNSS-R. For this purpose, utilized existing the Signal to noise ratio (SNR) data from ANMU, DATC, FASA, SINP and TEKR of TUSAGA-Active network, MERS from IGS network and SAME constituted from TUBITAK 1001 project GNSS stations. The dominant multipath frequency of SNR signal was computed with Lomb-Scargle periodogram (LSP). Consequently, MERS and TEKR stations were found to be suitable for sea level determination by using GNSS-R because these stations have a strong reflection amplitudes and significant observations. The GNSS-based sea level results for these stations were compared to sea level observations from nearby tide gauges. The comparison shows a agreement with a correlation coefficient of 0.76 and 0.91 , respectively.

Keywords: Sea level, GNSS reflectometry, Signal to noise ratio, Lomb-Scarge periodogram 


\section{Giriş}

Küresel ısınmayla birlikte atmosfer ve okyanuslar ısınmış, kar ve buz kütleleri zarar görmüş, rüzgar ve fırtına frekansları değişmiştir. Bununla birlikte buzullarda erime, okyanus ve deniz suyu seviyelerinde yükselme meydana gelmektedir. Antarktika ve Grönland'daki buz kütleleri erimenin hızlandığını göstermektedir. Üstelik deniz suyunun 1sıl genleşmesi, atmosferik değişimler ve okyanus sirkülasyonu gibi küresel ısınmanın diğer etkileri de deniz seviyesini etkilemeye devam edecektir (Löfgren, Haas, \& Scherneck, 2011). Deniz seviyesi yükselmesinin hızlanması ile 1950’den bu yana gözlemlenen ekstrem olayların düzeninde de değişiklikler görünmektedir. Uluslararası İklim Değişikliği Paneli’nin (Intergovernmental Panel on Climate Change, IPCC) AR4 (Fourth Assessment Report-2007) raporunda 20. yüzyılda deniz seviyesindeki ortalama artış $1.7 \mathrm{~mm} / \mathrm{y}$ 1l, 1961-2003 periyodunda $1.8 \mathrm{~mm} / \mathrm{y}$ 1l, 1993-2003 periyodunda ise $3.1 \mathrm{~mm} / \mathrm{y}$ 1l olarak belirlenmiştir (IPCC, 2007). IPCC AR5 (Fifth Assessment Report-2013) raporunda ise emisyon senaryosunun en kötü durumunda deniz seviyesinin 2100 yılına kadar $61 \mathrm{~cm}$ ila $1.1 \mathrm{~m}$ arasında artması beklenmektedir (IPCC, 2013). Deniz seviyesindeki hızlı artış ile kıyı alanları ilerleyen yıllar içerisinde artan doğal tehlikelere maruz kalacaktır. Bu tehlikeler; yükselen ortalama deniz seviyesinde toprağın sürekli su altında kalması, sık sık kıyı taşkınlarının yaşanması, artan kıyı erozyonu, kıyı ekosisteminin kaybı veya değişmesi, toprak ve yeraltı suyunun tuzlanması, drenaj engeli olarak sıralanabilmektedir. Türkiye'de yapılan çalışmalar, özellikle deniz seviyesinin altında olan delta ovaları gibi bazı kıyısal alanların deniz seviyesi yükselmesinden büyük ölçüde etkileneceğini göstermiştir (Simav, 2012).

Deniz seviyesi değişimi, farklı oranlarda, geniş zaman ölçeğinde ve konuma göre değişerek meydana gelmektedir. Son birkaç on yilda uydu verilerinden tahmin edilen küresel ortalama oran $\pm 3 \mathrm{~mm} / \mathrm{y} 1 \mathrm{l}$ olarak belirtilmiştir (Cazenave vd., 2014). Şekil 1'de, 1992 ve 2020 periyodunda uydu altimetreden elde edilen bölgesel deniz seviyesi trendleri gösterilmektedir. Şekilden de görüldüğü üzere deniz seviyesinde farklı oranlarda artan yönde trendler mevcuttur. Fakat bu oranlar dünya genelinde farklılıklar göstermektedir. Bu nedenle, gelecekte deniz seviyesinde meydana gelecek olan değişimin kestirilmesi ve değişiminden etkilenecek olan bölgelerin tespiti ve alınacak önlemler önemli olmaktadır.

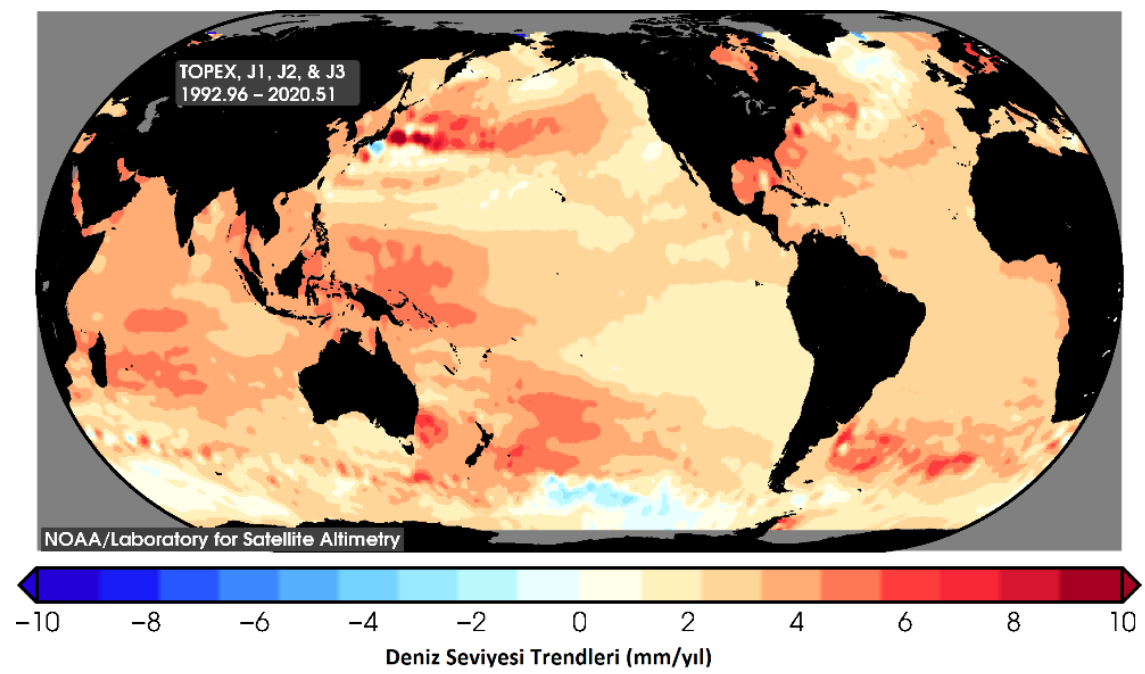

Şekil 1: Bölgesel deniz seviyesi trendleri. Bu harita TOPEX/Poseidon (T/P), Jason-1, Jason-2, and Jason-3 uydu misyonlarından elde edilen verilerin analizi sonucunda ortaya çıkmıştır. Bölgesel farkların -10 ile +10 mm arasında olduğu görülmektedir (URL-1).

Deniz seviyesi değişimi temelde mareograf ve uydu altimetre teknikleri kullanılarak belirlenmektedir. Genel olarak bakıldığında, lokal deniz seviyesi değişimlerini belirlemek için geleneksel olarak mareograf istasyonları kullanılmaktadır. $\mathrm{Bu}$ istasyonlarla deniz seviyesinin belirlenmesi, yer yüzeyi ile deniz yüzeyi arasındaki düşey mesafenin ölçülmesi esasına dayanmaktadır. Fakat geleneksel mareograf ölçümleri sadece deniz seviyesi gözlemlerini içermemektedir, aynı zamanda 
düşey yüzey hareketlerinden de etkilenmektedir. Buzul İzostatik Ayarı (Glacial Isostatic Adjustment, GCI), kosismik ve postsismik deformasyonlar, arazi çökmesi gibi etkenler mareograflarla kesin deniz seviyesinin ölçülmesini zorlaştırmaktadır. Bunun sonucunda deniz seviyesi gözlemlerinde belirsizlikler meydana gelmektedir. Dolayısıyla, mareograf ölçümlerinin düşey yüzey hareketine karşı düzeltilmesi gerekmektedir. Günümüzde, bazı mareograf istasyonları bu duruma karşı GPS ile entegre olarak hizmet vermektedir. Fakat bu tarz istasyonların bulunması maalesef zordur. Diğer bir teknik olan uydu altimetre ise yer gravite merkezine göre deniz seviyesini ölçmektedir ve bu nedenle yer merkezli etkilerden etkilenmemektedir. Fakat literatürdeki çalışmalara bakıldığında, uydu altimetre tekniğinin kıyı alanlarında yeterli duyarlıkta sonuçlar vermediği gözükmektedir. Geniş ayak izine sahip olan uydu altimetrede geri dönen dalga boyu kıyllara yaklaşırken şiddetli bir şekilde kirlenmektedir. Bu durum, gözlem doğruluğunun azalmasına neden olmaktadır (Chelton, Ries, Haines, Fu, \& Callahan, 2001;Lee vd., 2019). Sonuç olarak, kıyı alanlarındaki deniz seviyesi değişimi doğruluğunu arttırmak için alternatif tekniklerin geliştirilmesi gerekmektedir.

Küresel Navigasyon Uydu Sistemleri Reflektometre (GNSS-R) yeni bir uydu tekniği olup yansıyan sinyali kullanarak başlıca deniz seviyesi (Larson, Löfgren, \& Haas, 2013a; Larson, Ray, Nievinski, \& Freymueller, 2013b; Larson, Ray, \& Williams, 2017), kar kalınlığı (Larson \& Nievinski, 2013), toprak nemi (Larson vd., 2008; Vey, Güntner, Wickert, Blume, \& Ramatschi, 2016) değişimini belirleme çalışmalarında kullanılmaktadır. Bu yöntem, mareograf ve uydu altimetreye göre daha yüksek konumsal ve zamansal çözünürlüğe sahiptir (Löfgren, Haas, \& Johansson, 2010).

GNSS sinyal yansıma etkisi ölçülerin doğruluğunu etkileyen büyük hata kaynaklarından biridir. Hassas konum belirleme için istenmeyen bu hata kaynağının deniz seviyesi gözlemlerinde kullanılması, Martin-Neira (1993) tarafından GNSS elektromanyetik dalgalarındaki doğrudan ve dolaylı sinyal girişimlerinin yansıma yüzeylerinin özelliklerinin kestirilmesinde ortaya atılmıştır. GNSS tabanlı mareograf ise ilk olarak Larson vd. (2013a) tarafından rölatif deniz seviyesi değişikliğini Sinyal Gürültü Oranı (Signal to Noise Ratio, SNR) gözlemlerini kullanarak ölçmek için sunulmuştur. Birçok araştırmacı tarafından SNR gözlemlerinden yararlanarak GNSS tabanlı deniz seviyesi gözlemlerinin hesaplandı̆̆ı ve bu gözlemlerin mareograf kayıtları ile karşılaştırıldığı çeşitli çalışmalar yapılımıştır (Larson vd., 2013a, 2013b, 2017; Santamaría-Gómez, Watson, Gravelle, King, \& Wöppelmann, 2015). Löfgren, Haas ve Scherneck (2014) dünyanın farklı bölgelerinde bulunan beş adet GPS istasyonunda kaydedilen SNR verilerini kullanarak deniz seviyesi gözlemlerini hesaplamıştır. Çalışmada istasyonun bulunduğu bölgenin, alıcı anteni ile yansıtıcı yüzey arasındaki düşey mesafenin, uydu yükseklik açısı ve azimut aralıklarının GNSS tabanlı deniz seviyesinin belirlenmesi üzerindeki etkileri analiz edilmiştir. Lee vd. (2019) yapmış olduğu çalışmada Tayvan'da bulunan üç adet GNSS istasyonuna ait GPS L1 frekansına ait SNR verilerini kullanarak gelgit değişiminin düşük olduğu bölgedeki istasyonlarda Lomb-Scargle periodogram (LSP) analizi, yüksek olduğu bölgedeki istasyonlarda ise harmonik analiz ile birlikte LSP analizi uygulamıştır. Sonuç olarak, harmonik analiz ve LSP analizinin bir arada kullanılması ile periodogramda doğru piklerin bulunma olasıllı̆ının yükseldiği görülmüştür. Tunalığlu, Doğan ve Durdağ (2019) Alaska'da bulunan AB33 istasyonuna ait SNR verilerini kullanarak kar kalınlığı değişimlerini incelemiştir. Elde edilen kar kalınlıklarını yerinden ölçüm verileri ile karşılaştırarak yüksek oranda bir korelasyon bulunmuştur. Selbesoğlu vd. (2019) GNSS meteorolojisi ve GNSS-R tekniklerini kullanarak Antarktika'da deniz seviyesi, kar/buzul ve su buharı değişimlerini gözlemlemiştir. Türkiye denizlerinde GNSS-R tekniğini kullanarak deniz seviyesi belirlenmesine yönelik araştırma ilk kez bu çalışmada yapılmaktadır.

Üç tarafı denizlerle çevrili olan ülkemizde deniz seviyesinin doğru ve hassas bir şekilde belirlenmesi önemlidir. Bu çalışmada, ülkemizde GNSS-R tekniği ile deniz seviyesi belirlenebilirliğinin araştırılması amaçlanmaktadır. Bunun için Türkiye kıyılarına yakın sabit GNSS istasyonları çalışma alanı olarak belirlenmiş̧ir. Her bir istasyona ait SNR verileri analiz edilmiş̧ir. Ardından, GNSS-R tabanlı deniz seviyesi gözlemleri LSP yöntemi kullanılarak belirlenmiştir. Son olarak, GNSS 
tabanlı elde edilen deniz seviyesi ile GNSS istasyonları yakınında bulunan mareograf gözlemleri karşılaştırılmıştır.

\section{Yöntem}

GNSS-R tekniği ile doğrudan gelen sinyal yerine yansıyan sinyal kullanılarak analizler yapılmaktadır. GNSS sinyal yansıma etkisi; faz, frekans ve genlik modülasyonları, yansıma yüzeyinin pürüzlülüğü, yansıma yüzeyinin geometrisi ve bileşeni gibi birçok faktörden kaynaklanmaktadır. Bu etkinin girişim desenleri kod, faz ve SNR ölçülerinde gözlemlenmektedir. Her bir GNSS alıcısı, yeryüzünden yansıyan çok sayıda GNSS sinyalini toplayabilmektedir. Bu bi-statik gözlem setleri farklı azimut ve yükseklik açılarında meydana gelmektedir (Li, 2018). Yansıyan sinyali en iyi şekilde almak için tasarlanan özel donanımlı GNSS aletlerini kullanan reflektometre çalışmalarının tersine jeodezik alıcılar doğrudan gelen ve yansıyan sinyallerin girişimlerini ölçmektedir (Larson vd., 2017). Literatürde, çift jeodezik alıcı (Right Hand Circularly Polarised (RHCP) ve Left Hand Circularly Polarised (LHCP), Şekil 2(a)) veya tek jeodezik alıcı (RHCP, Şekil 2(b)) kullanılarak yapılan GNSS-R çalışmaları mevcuttur (Larson vd., 2013a, 2013b, 2017; Lee vd., 2019; Löfgren vd., 2010; Santamaría-Gómez \& Watson, 2017).

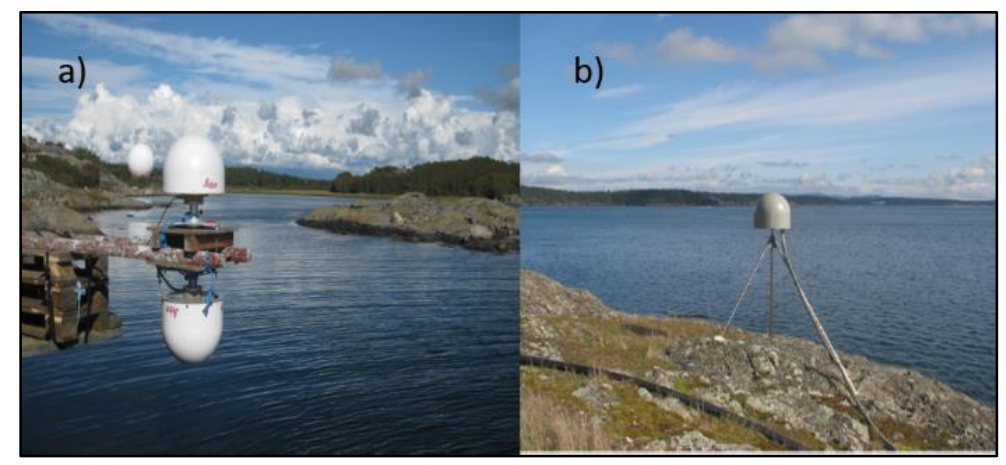

Şekil 2: GNSS-R jeodezik alıcıları. Soldaki (a) resim Onsala Uzay Gözlem Evine (GTGU) ait olup zenit (RHCP) ve nadir (LHCP) yönünde olmak üzere çift antene sahiptir. Sağdaki (b) resim ise Friday Liman GPS istasyonu (SC02) olup sadece zenit (RHCP) yönünde tek bir alıcıya sahiptir (Kaynak: (a) Johan Löfgren, Chalmers University of Technology, (b) UNAVCO (URL-2)).

Yer merkezli GNSS-R için iki yöntem mevcuttur. Bunlardan biri zenit yönlü RHCP anteni kullanılan SNR yöntemi, diğeri ise zenit yönlü RHCP ve nadir yönlü LHCP antenlerinin kullanıldığı faz gecikmesi yöntemidir. Faz gecikmesi yönteminde, doğrudan gelen ve yansıyan sinyal arasındaki faz farkını belirlemek için iki anten kullanılmaktadır. SNR yönteminde ise tek anten yeterli olmaktadır. GNSS antenine doğrudan ve dolaylı gelen sinyaller anten faz merkezinde birleşmekte olup aynı alıcıya kaydedilmektedir. Bu iki yöntem karşılaştırıldığında faz gecikmesi yönteminin SNR yönteminden daha doğru sonuçlar verdiği bilinmektedir. Fakat nadir yönlü LHCP anteninin donanımını sağlamak çoğunlukla zordur. Dünya genelinde, başta Onsala Uzay Gözlem Evi (GTGU) olmak üzere çok az sayıda istasyonda mevcuttur. Bu nedenle, kıyı alanlarındaki GNSS istasyonlarında büyük çoğunlukta SNR yöntemi kullanılmaktadır. Ayrıca, doğrudan gelen ve yansıyan sinyalin girişim desenlerinin en fazla SNR verilerinde gözlemlenmesi, SNR verilerinin rüzgar ve dalga şartlarına karşı hassasiyetinin faz gecikmesi yöntemine göre daha az olması, tek jeodezik anten kullanılmasından dolayı maliyetinin daha düşük olması vb. özellikler bu tekniğin avantajları arasında gösterilmektedir. Bu çalışmada, bölgesel deniz seviyesi değişimleri tek jeodezik GNSS alıcısından alınan GPS sinyalleri kullanılarak hesaplanacaktır (Şekil 3). 


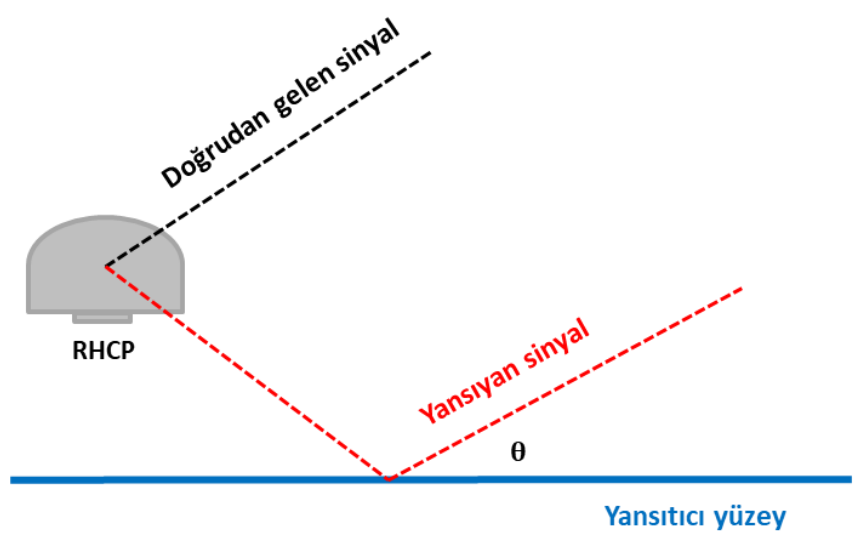

Şekil 3: Tek jeodezik alıcı ile GNSS-R şematik gösterim. $\theta$; uydu yükseklik açısını ifade etmektedir.

GNSS uydularının gökyüzünde hareketi sırasında yansıma geometrisi değişmektedir. Bu durumda, SNR gözlemlerinin genliği de değişmektedir (Löfgren, 2014). SNR, zamanın fonksiyonu olarak kaydedilmektedir. Aynı zamanda ufuk çizgisine göre uydu yükseklik açısının da fonksiyonudur. Birinci Fresnel bölgesi (First Fresnel Zone, FFZ) hesaplanarak elde edilen yansıma bölgeleri de uydu yükseklik açısı, dalga boyu ve reflektör yüksekliğine bağlı olarak değişmektedir. Uydu yükseklik açısı arttıkça yansıma bölgeleri küçülmektedir ve antene yakın olmaktadır (Larson vd., 2017). Uydudan GNSS alıcısına doğrudan gelen ve yansıyan sinyaller arasındaki girişim ise düşük yükseklik açılarında $\left(0^{\circ}-25^{\circ}\right)$ daha fazla olmaktadır. Uydu yükseklik açısı $25^{\circ}$ 'nin üzerinde olduğunda sinyal yansıma etkisi küçülmekte olup yansıma bölgeleri çoğunlukla deniz alanlarının yanında karasal alanları da içermektedir (Larson vd., 2013b).

\subsection{Sinyal Gürültü Oranının Belirlenmesi}

GNSS alıcısına gelen sinyalin şiddetini ifade eden S1 ve S2 gözlemleri Alıcıdan Bağımsız Değişim Formatında (Receiver INdependent Exchange Format, RINEX) arşivlenmektedir. S1, S2 değerleri taşıyıcı-gürültü yoğunluk oranına (carrier to noise density ratio, $\left.C / N_{0}\right)$ karşılık gelmektedir.

$C / N_{0}=\frac{\text { Sinyal Gücü }}{\text { Sinyal Gücü Spektral Yoğunluğu }}$

SNR ise;

$S N R=\frac{C / N_{0}}{B}$

şeklinde elde edilir. Burada $B$, gürültü bant genişliğini ifade etmektedir (Joseph, 2010). Buradan elde edilen SNR logaritmik ölçekte desibel birimindedir. SNR ölçümleri logaritmik ölçekte kullanıldığında, alıcının gürültü bant genişliği ölçek faktörü olarak davranmaktadır ve bu nedenle SNR salınımlarının tahmin edilen frekansları üzerinde etkiye sahip olmamaktadır (Santamaría-Gómez \& Watson, 2017). Literatürdeki çalışmalara bakıldığında, SNR ölçümlerinin lineer ölçeğe dönüştürülerek kullanıldığı görülmektedir. Ölçümlerin lineer ölçeğe dönüşümü ile SNR verileri volts/volts veya watts/watts biriminde elde edilmektedir. Alıcıya gelen sinyalin SNR ile olan ilişkisi;

$S N R^{2} \approx A_{c}^{2}=A_{d}^{2}+A_{r}^{2}+2 A_{d} A_{r} \cos \psi$

olarak ifade edilir. Burada, $A_{c}$; girişim yapan sinyalin genliği, $A_{d}$; doğrudan gelen sinyalin genliği, $A_{r}$; yansıyan sinyalin genliği, $\Psi$ ise iki sinyal arasındaki faz farkıdır (Larson vd., 2008). 
Zenit yönlü RHCP anteninin amacı, doğrudan gelen sinyali büyütmek ve yansıyan sinyali bastırmak olmasına rağmen yansıyan sinyalden gelen enerjiyi tamamen reddetmediği bilinmektedir (Larson vd., 2013a). GNSS antenine doğrudan ve dolaylı olarak gelen sinyaller anten faz merkezinde birleşmektedir ve aynı alıcıya kaydedilmektedir. Dolayısıyla, jeodezik GNSS alıcısından alınan yansıyan sinyalin içerisinde doğrudan gelen sinyalin etkisi de bulunmaktadır. Doğrudan gelen sinyalin etkisini kaldırarak doğrudan trendleri bulmak için tüm veriye düşük dereceli polinom veya yüksek geçirgenli filtre uygulanarak trend veri setinden çıkarılmaktadır. Böylece, doğrudan gelen sinyalin etkisinin kaldırıldığı trendden arındırılmış (detrend edilmiş- $\delta S N R$ ) SNR verileri elde edilmektedir. Elde edilen veri, sinyal yansıma etkisinin bileşenlerini içermektedir. Trendden arındırılmış SNR verisi için sinyal yansıma etkisi salınımları;

$\delta S N R=A \cos \left(\frac{4 \pi h}{\lambda} \sin \theta+\varphi\right)$

şeklindedir. Burada, $A$; genlik, $h$; anten faz merkezi ile yansıma yüzeyi arasındaki düşey mesafe (reflektör yüksekliği), $\lambda$; GNSS taşıyıcı dalga boyu, $\theta$; uydu yükseklik açısını ifade etmektedir (Larson vd., 2013a). Uydu yükseklik açısının sinüsüne karşılık gelen $\delta S N R$ frekansı,

$f_{\delta S N R \rightarrow \sin \theta}=\frac{d \delta S N R}{d \sin \theta}=\frac{f_{\psi \rightarrow \sin \theta}}{2 \pi}=\frac{2 \dot{h}}{\lambda} \frac{\tan \theta}{\dot{\theta}}+\frac{2 h}{\lambda}$

şeklindedir. Burada, $\dot{h}$ reflektör yüksekliği sabit alındığında ihmal edilebilir. Bu durumda,

$f_{\delta S N R \rightarrow x}=\frac{2 h}{\lambda}$

şeklindedir. Trendden arındırılmış SNR verilerinin frekansı reflektör yüksekliğine $(h)$ bağlıdır. Burada, $h$ bileşeni spektral analiz yöntemleri kullanılarak hesaplanmaktadır (Wan, Larson, Small, Chew \& Braun, 2015).

\subsection{GNSS Yansıma Etkisi Frekansının Belirlenmesi}

SNR salınımlarının frekansı, yansıma yüzeyine olan düşey mesafe ve uydu yüksekliğine bağlıdır. Yansıyan yüzey üzerinden daha yüksek anten yükseklikleri SNR serilerinde yüksek frekans salınımlarını belirtmektedir. $h$, reflektör yüksekliğini hesaplamak için trendden arındırılmış SNR salınımlarındaki dominant frekansının belirlenmesi gerekmektedir. Dominant frekansı çıkarmak için LSP, Hızlı Fourier Dönüşümü, Dalgacık Dönüşümü gibi çeşitli spektral analiz yöntemleri mevcuttur.

SNR verileri zaman içerisinde eşit olarak örneklenmektedir. Fakat $\delta S N R$ uydu yükseklik açısının sinüs fonksiyonu olarak eşit şekilde örneklenmemektedir. Bu yüzden, düzenli olarak örneklenmemiş veri setinde spektral analiz yapmak zor olmaktadır. Literatürde yapılan çalışmalara bakıldığında en uygun yöntemin LSP olduğu görülmüştür. Bu yöntem düzensiz aralıklı veriyi işleyebilmektedir (Larson vd., 2013a). Aynı zamanda, En Küçük Kareler Spektral Analizi olarak da adlandırılmaktadır. LSP, sinüzoidal modele dayalı sinyalin her bir zamanının yerine her bir noktanın spektral gücünü tahmin etmektedir (Löfgren, 2014). Dominant frekans en yüksek spektral güce denk gelmektedir ve Eşitlik (6) kullanılarak reflektör yüksekliğine dönüştürülmektedir. Burada elde edilen büyük reflektör yüksekliğinde yani deniz yüzeyi ile anten arasındaki mesafe geniş olduğu durumda deniz seviyesi düşük olmaktadır.

\section{3. Çalışma Alanı ve Veri}

Çalışma kapsamında Türkiye'nin farklı denizlerinde kıyıya yakın GNSS istasyonlarının GNSS-R tekniği ile deniz seviyesi gözlemlerinin yapılmasına katkısının belirlenmesi amaçlanmaktadır. Bu amaçla, Türkiye Ulusal Sabit GNSS Ağı Aktif 
(TUSAGA-Aktif) bünyesinde bulunan Akdeniz'de ANMU, Ege'de DATC, Marmara'da TEKR ve Karadeniz'de SINP, FASA istasyonları (URL-3), yine Akdeniz bölgesinde Uluslararası GNSS Servisine (International GNSS Service, IGS) ait MERS istasyonu (URL-2) ve Karadeniz bölgesinde 116Y186 TÜBİTAK 1001 projesi kapsamında Samsun'da tesis edilen SAME istasyonu çalışmada kullanılmıştır (Şekil 4).

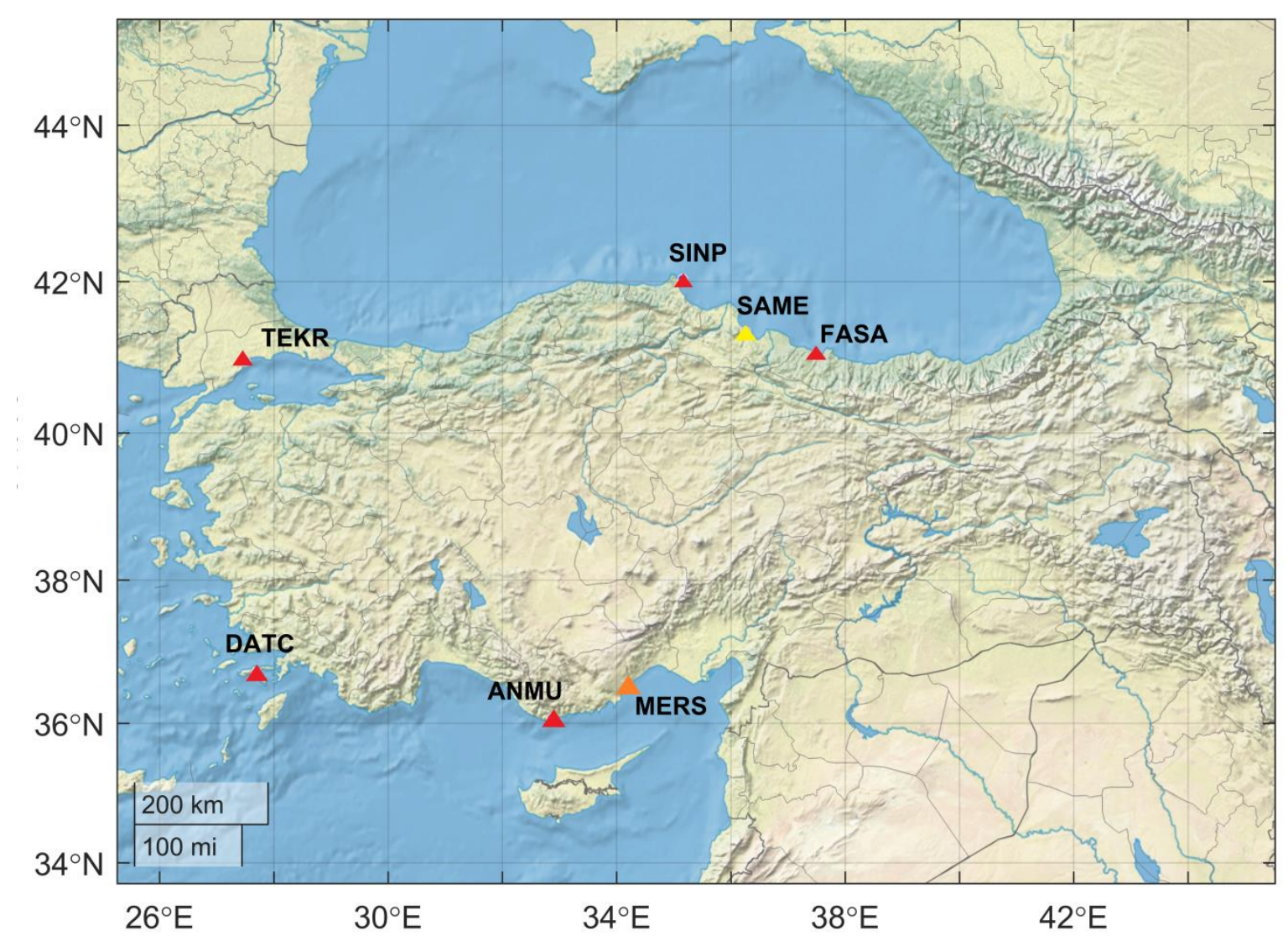

Şekil 4: Çalışmada kullanılan istasyonlar. Kırmızı renk ile gösterilen istasyonlar TUSAGA-Aktif, sarı renk 116 Y186 no'lu TÜBITAK 1001 projesi kapsamında tesis edilen sabit GNSS istasyonu, turuncu renkle gösterilen istasyon IGS ağına bağlı istasyondur.

Çalışmada, her bir istasyona ait GPS L1 frekansı SNR verileri kullanılmıştır. ANMU, DATC, FASA, MERS, SINP ve TEKR istasyonları için zaman aralığı 1 Mayıs 2020 ve 31 Mayıs 2020 olup veri kayıt aralığ1 ise 30 saniyedir. SAME istasyonunda ise 1 Mart 2018 ve 30 Mart 2018 zaman aralığında 15 saniyelik veriler kullanılmıştır. Yapılan analizler sonucunda, elde edilen GNSS tabanlı deniz seviyesi verilerini karşılaştırıp doğrulama yapmak için istasyon yakınında bulunan Türkiye Ulusal Deniz Seviyesi İzleme Servisi’ne (TUDES) bağlı mareograf istasyon gözlemleri kullanılmıştır (URL-4). Çalışma kapsamında kullanılan sabit GNSS istasyonlarına ait bilgiler Tablo 1'de gösterilmektedir.

\section{Veri Analizi}

Çalışmada öncelikle, ANMU, DATC, FASA, MERS, SAME, SINP ve TEKR istasyonlarında ayrı ayrı azimut ve yükseklik açıları için maskeler uygulanmıştır. Azimut ve yükseklik açısı maskelerinin başlangıç ve bitiş değerlerine karar vermek için Roesler ve Larson (2018) tarafindan sunulan FresnelMaps yazılımına benzer olarak istasyonlara ait Fresnel bölgeleri belirlenmiştir. Fresnel bölgelerinin büyük yarı ekseni $(a)$ ve küçük yarı ekseni $(b)$,

$a=\frac{\sqrt{\lambda h \sin \theta}}{\sin ^{2} \theta}$ 
$b=\frac{\sqrt{\lambda h \sin \theta}}{\sin \theta}$

şeklindedir. Burada, $\lambda$; GPS taşıyıcı dalga boyu, $h$; alıcı anten yüksekliği ve $\theta$; uydu yükseklik açısını ifade etmektedir (Larson \& Nievinski, 2013; Löfgren, 2014). Her bir istasyon için SNR salınımlarının net olarak görüldüğ̈ $5^{\circ}, 1^{\circ}, 1^{\circ}, 2^{\circ}$ ve $25^{\circ}$ uydu yükseklik açısına sahip uydu izleri için hesaplanan Fresnel bölgeleri Google Earth görüntüsü üzerinde gösterilmiştir (Şekil 5). Azimut aralıkları ise, Fresnel bölgelerinde denizi kapsayan alanlara göre belirlenmiştir. Aynı şekilde her bir istasyon için belirlenen uydu yükseklik açısı aralıkları da denizi kapsayan uydu izlerini içerecek şekilde seçilmiştir. Buna göre ANMU, DATC, FASA, MERS, SAME, SINP ve TEKR istasyonlarında sirasıyla $12^{\circ}, 15^{\circ}, 10^{\circ}, 20^{\circ}, 20^{\circ}, 10^{\circ}$ ve $20^{\circ}$ den büyük uydu yükseklik açılarında Fresnel bölgelerinin karasal alanları içerdiği görülmüştür. Çalışmada kullanılan istasyonlara ait azimut ve yükseklik açısı maskeleri Tablo 2'de gösterilmiştir.

Tablo 1: Çalışmada kullanılan istasyon bilgileri

\begin{tabular}{|c|c|c|c|c|c|c|c|c|c|}
\hline $\begin{array}{c}\text { İstasyon } \\
\text { Adı }\end{array}$ & Bölge & $\begin{array}{c}\text { İstasyon } \\
\text { Ă̆gl }\end{array}$ & $\begin{array}{c}\text { Enlem } \\
\text { (derece) }\end{array}$ & $\begin{array}{l}\text { Boylam } \\
\text { (derece) }\end{array}$ & $\begin{array}{c}\text { Deniz } \\
\text { Yüzeyinden } \\
\text { Yükseklik }\end{array}$ & $\begin{array}{c}\text { GPS } \\
\text { frekansı }\end{array}$ & $\begin{array}{c}\text { Veri } \\
\text { Kayıt } \\
\text { Aralığı }\end{array}$ & Periyot & $\begin{array}{l}\text { Mareograf } \\
\text { İstasyonu }\end{array}$ \\
\hline ANMU & Akdeniz & $\begin{array}{c}\text { TUSAGA- } \\
\text { Aktif }\end{array}$ & 36.0690 & 32.8651 & $12 \mathrm{~m}$ & L1 & $30 \mathrm{sn}$ & $\begin{array}{l}01.05 .2020- \\
31.05 .2020\end{array}$ & Bozyazı \\
\hline DATC & Ege & $\begin{array}{c}\text { TUSAGA- } \\
\text { Aktif }\end{array}$ & 36.7085 & 27.6918 & $31 \mathrm{~m}$ & L1 & $30 \mathrm{sn}$ & $\begin{array}{l}01.05 .2020- \\
31.05 .2020\end{array}$ & - \\
\hline FASA & Karadeniz & $\begin{array}{c}\text { TUSAGA- } \\
\text { Aktif }\end{array}$ & 41.0455 & 37.4847 & $15 \mathrm{~m}$ & L1 & $30 \mathrm{sn}$ & $\begin{array}{l}01.05 .2020- \\
31.05 .2020\end{array}$ & - \\
\hline MERS & Akdeniz & IGS & 36.5663 & 34.2558 & $12 \mathrm{~m}$ & L1 & $30 \mathrm{sn}$ & $\begin{array}{l}01.05 .2020- \\
31.05 .2020\end{array}$ & Erdemli \\
\hline SAME & Karadeniz & 116Y186 & 41.3438 & 36.2555 & $16 \mathrm{~m}$ & L1 & $15 \mathrm{sn}$ & $\begin{array}{l}01.03 .2018- \\
30.03 .2018\end{array}$ & - \\
\hline SINP & Karadeniz & $\begin{array}{c}\text { TUSAGA- } \\
\text { Aktif }\end{array}$ & 42.0302 & 35.1539 & $28 \mathrm{~m}$ & L1 & $30 \mathrm{sn}$ & $\begin{array}{l}01.05 .2020- \\
31.05 .2020\end{array}$ & Sinop \\
\hline TEKR & Marmara & $\begin{array}{c}\text { TUSAGA- } \\
\text { Aktif }\end{array}$ & 40.9583 & 27.4964 & $10 \mathrm{~m}$ & L1 & $30 \mathrm{sn}$ & $\begin{array}{l}01.05 .2020- \\
31.05 .2020\end{array}$ & $\begin{array}{l}\text { Marmara } \\
\text { Ereğlisi }\end{array}$ \\
\hline
\end{tabular}

Uydu yükseklik açısı ve azimut aralıkları belirlendikten sonra her bir sabit GNSS istasyonuna ait Tablo 2'de belirtilen aralıklardaki uydu izlerinin SNR verileri kullanılmıştır. SNR salınımları doğrudan gelen ve yansıyan sinyalleri içermektedir. SNR salınımlarındaki doğrudan gelen sinyalin etkisinden kurtulmak için düşük dereceli polinom geçirilerek Eşitlik 4'te gösterildiği şekilde trendden arındırılmış SNR verileri elde edilmiştir. Veriye uygun polinomun derecesine karar vermeden önce parametre anlamlılık testi yapılmıştır. Yapılan anlamlılık testi sonucunda birinci dereceden polinom tüm istasyon verilerinde anlamlı sonuç vermiştir. Ardından reflektör yüksekliklerini hesaplamak için trendden arındırılmış SNR verilerine LSP analizi uygulanmıştır. Aynı zamanda, yapılan LSP analizi ile birlikte ilgili istasyonların GNSS-R ile deniz seviyesi belirlenmesine uygun olup olmadığı tespit edilmeye çalışılmıştır. Trendden arındırılmış SNR salınımlarından LSP analizi sonucunda, en yüksek spektral güce karşılık gelen dominant yansıma etkisi frekansı Eşitlik 6 kullanılarak reflektör yüksekliğine dönüştürülmüş olup deniz seviyesi elde edilmiştir. Burada periodogramın tek bir anlamlı pik içermesi önemlidir. LSP ile elde edilen pik değerlerinin anlamlı olup olmadığına karar vermek için Larson vd. (2013a) tarafindan yapılan çalışmaya benzer şekilde pik-gürültü oranı testi uygulanmıştır. Buna göre en yüksek reflektör yükssekliği genliğinin gürültüye oranı 3'ten küçük olan yansımalar anlamsız olup analizde kullanılmamıştır. Eğer periodogramda birden çok pik elde ediliyorsa dominant frekans hesaplanamamıştır ve reflektör yüksekliğine dönüştürülememiştir. Bu durum veri kalitesinden veya istasyon yakınındaki başka yansıtıcı etkilerden kaynaklanabilmektedir (Lee vd., 2019). Sonuç olarak, zayıf yansıyan bu sinyallerden anlamlı reflektör yükseklikleri hesaplanamadığından ilgili istasyonun GNSS-R ile deniz seviyesi belirlenmesine elverişli olmadığına karar verilmiştir. Her bir istasyon için yukarıda belirtilen şartları sağlayan uydu izlerinden elde edilen reflektör yüksekliklerinin ortalaması alınarak günlük reflektör yükseklikleri hesaplanmıştır. 
Son olarak, GNSS tabanlı deniz seviyesi gözlemleri, ilgili GNSS istasyonuna yakın mareograf kayıtları ile karşılaştırılmıştır. Her iki deniz seviyesi gözlem verileri arasındaki Pearson korelasyon katsayısı,

$r_{x y}=\frac{\sum_{i=1}^{n}\left(x_{i}-\bar{x}\right)\left(y_{i}-\bar{y}\right)}{(n-1) S_{x} S_{y}}$

şeklinde hesaplanmıştır. Burada $n$; veri çiftlerini $\left(x_{i}, y_{i}\right), \bar{x}$ ve $\bar{y}$; değişkenlerin ortalamalarını, $S_{x}$ ve $S_{y}$ ise değişkenlerin standart sapmalarını ifade etmektedir (Tüysüz \& Yaylalı Abanuz, 2012).

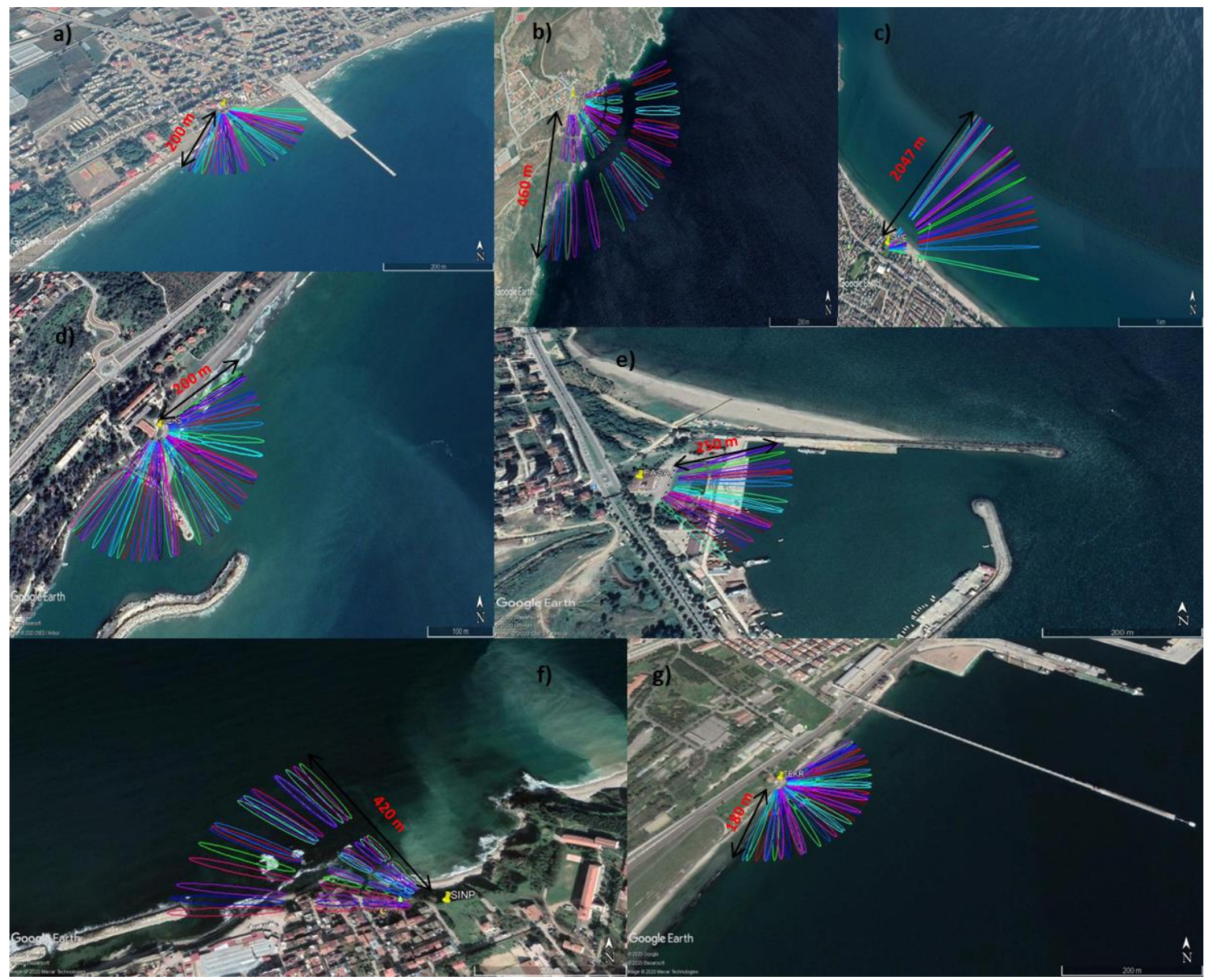

Şekil 5: Çalışmada kullanılan sabit GNSS istasyonları Fresnel bölge resimleri: ANMU (a); DATC (b); SAME (c); MERS (d); FASA (e); SINP (f); TEKR (g).

Tablo 2: Çalışmada kullanılan istasyon bilgileri

\begin{tabular}{|c|c|c|c|c|c|c|c|}
\hline & ANMU & DATC & FASA & MERS & SAME & SINP & TEKR \\
\hline Azimut (derece) & $120^{\circ}-200^{\circ}$ & $60^{\circ}-150^{\circ}$ & $60^{\circ}-100^{\circ}$ & $60^{\circ}-160^{\circ}$ & $0^{\circ}-90^{\circ}$ & $300^{\circ}-330^{\circ}$ & $60^{\circ}-180^{\circ}$ \\
\hline $\begin{array}{l}\text { Uydu Yükseklik } \\
\text { Açıs1 (derece) }\end{array}$ & $5^{\circ}-12^{\circ}$ & $5^{\circ}-15^{\circ}$ & $5^{\circ}-10^{\circ}$ & $5^{\circ}-20^{\circ}$ & $1^{\circ}-20^{\circ}$ & $5^{\circ}-10^{\circ}$ & $5^{\circ}-20^{\circ}$ \\
\hline
\end{tabular}

GNSS tabanlı deniz seviyesi gözlemleri anten faz merkezine, mareograf kayıtları ise mareograf istasyonunun bulunduğu yere göre referanslıdır. Bu nedenle, iki gözlem değeri arasında datum farklılığı vardır. Bu farkı kaldırmak için, karşılaştırma yapmadan önce her iki yöntemle elde edilen deniz seviyesi zaman serilerinden ortalama değer çıkarılmıştır. Çalışmaya ilişkin iş akış şeması Şekil 6'da gösterilmiştir. 


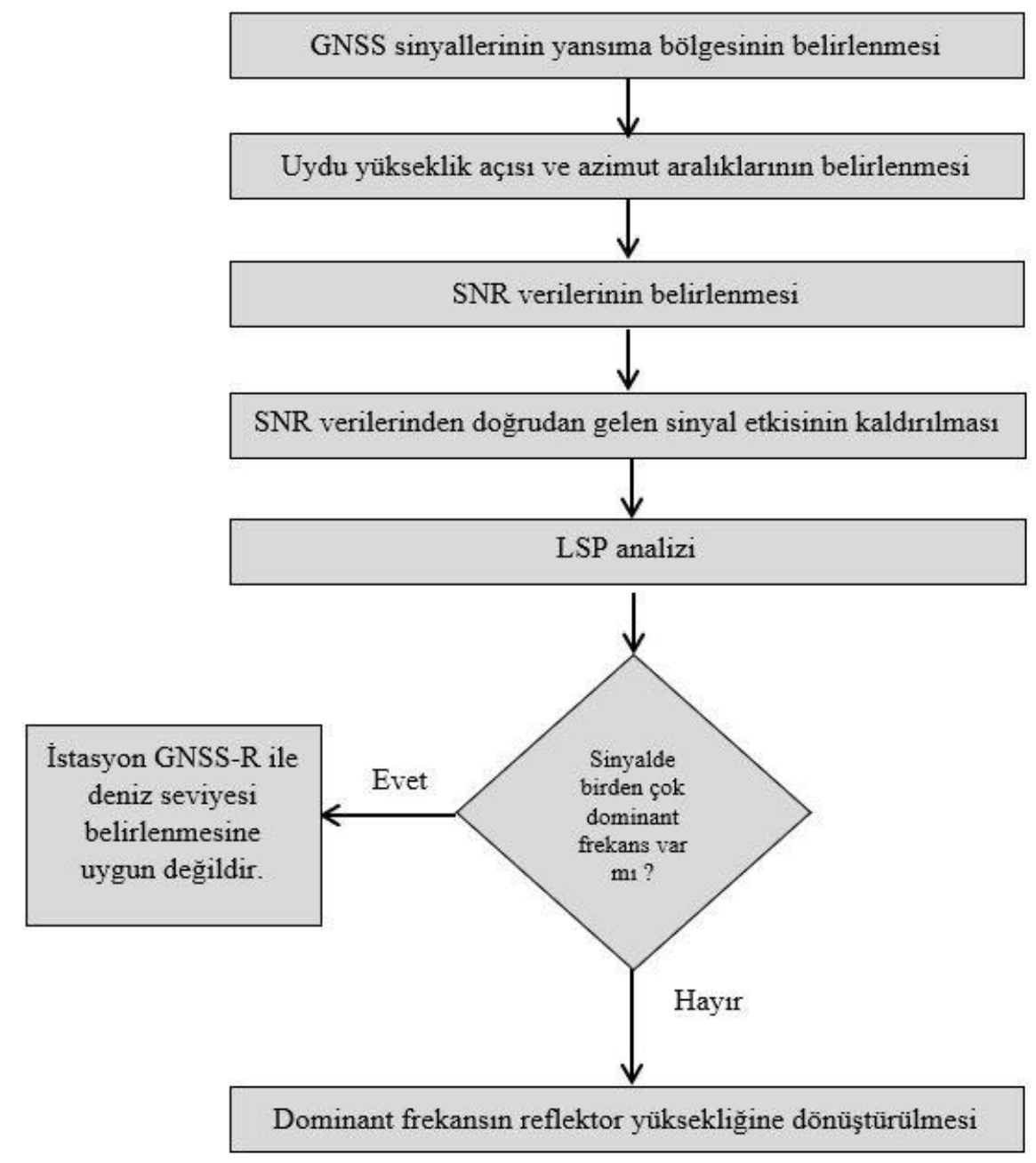

Şekil 6: GNSS-R ile deniz seviyesi belirlenmesi iş akış şeması

Akdeniz bölgesinde bulunan ANMU istasyonunda $5^{\circ}-12^{\circ}$ uydu yükseklik açısı ve $120^{\circ}-200^{\circ}$ azimut aralığındaki uydu izlerine ait SNR verileri kullanılmıştır. Şekil 7'de Pseudo Random Noise (PRN) 2 numaralı GPS uydu izine ait SNR salınımları ve LSP sonuçları gösterilmektedir. Uydu yükseklik açısı arttıkça sinyal yansıma etkisi ile beraber SNR verilerinin artan yönde eğilim göstermesi gerekirken ilgili istasyonda SNR salınımları aynı seviyede devam etmekte olup istenilen sıklıkta veri bulunmamaktadır (Şekil 7(a)). Uygulanan uydu yükseklik açısı ve azimut maskesi ile elde edilen SNR verilerinin yeterli düzeyde olmadığı görülmüştür. LSP analizi sonucuna bakıldığında ilgili istasyona ait trendden arındırılmış SNR verilerinin dominant frekansa sahip olduğu görülmektedir ve bu frekansa karşıllk gelen reflektör yüksekliği hesaplanabilmektedir. 

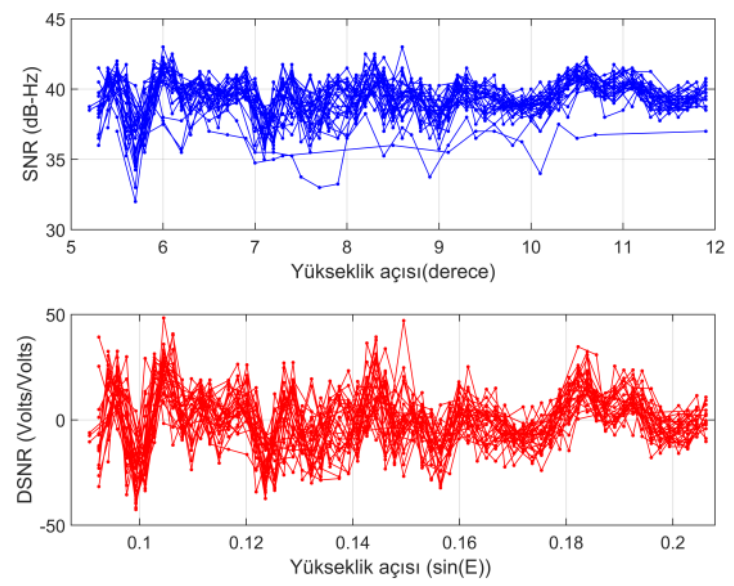

(a)

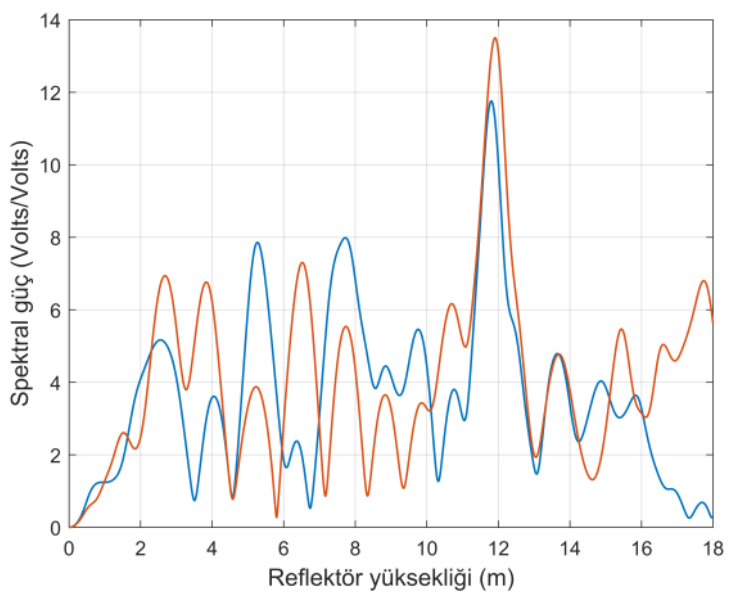

(b)

Şekil 7: (a) ANMU istasyonunda ait SNR salınımları. Mavi renk doğrudan gelen ve yansıyan sinyali içeren SNR, kırmızı renk ise doğrudan gelen sinyalin etkisinden arındırılmış DSNR salınımlarını göstermektedir. (b) ANMU istasyonuna ait doğrudan gelen sinyal etkisinin kaldırıldığı SNR verileri kullanılarak DOY 122 ve DOY 123 için hesaplanan LSP salınımları

Fakat GNSS-R ile hesaplanan deniz seviyesi verileri istasyona en yakın Bozyazı mareograf istasyonu gözlemleri ile karşılaştırıldığında her iki deniz seviyesi gözlemleri arasında korelasyon olmadığı görülmüştür (Şekil 8). ANMU istasyonunda belirlenen uydu yükseklik açısı aralığındaki yetersiz SNR verisi ve zayıf yansıma genlikleri sonuca etki eden faktörler olarak değerlendirilmiştir.

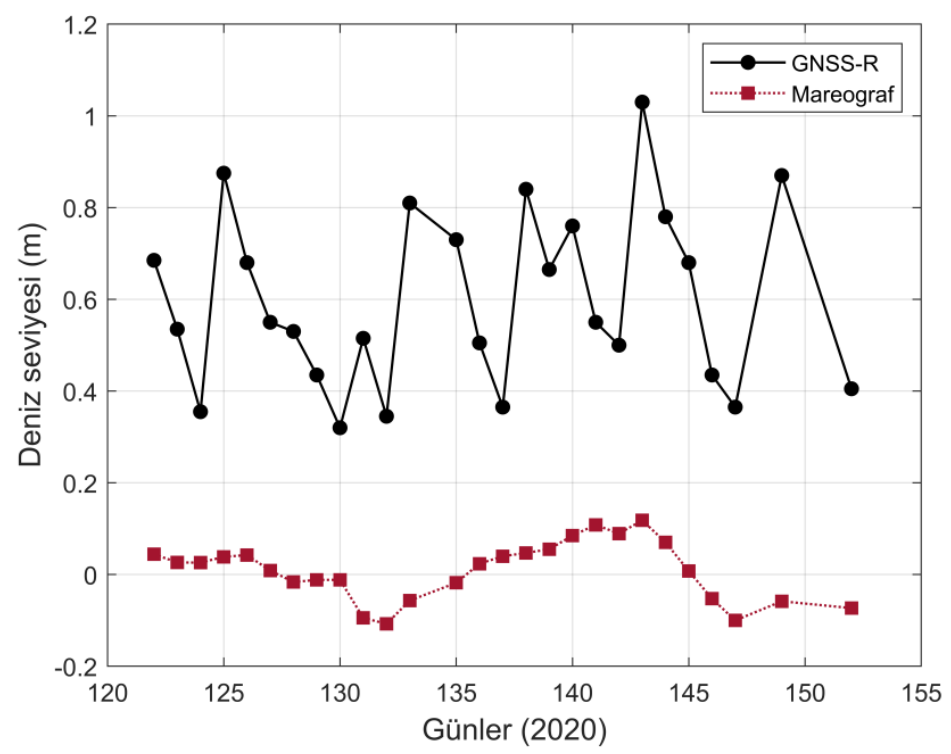

Şekil 8: ANMU istasyonu GNSS-R ile tahmin edilen deniz seviyesi ve Bozyazı mareograf istasyonu deniz seviyesi gözlemleri karşılaştırması

Ege bölgesinde bulunan DATC istasyonuna ait $5^{\circ}-15^{\circ}$ uydu yükseklik açısı ve $60^{\circ}-150^{\circ}$ azimut aralığındaki uydu izlerine ait SNR verileri kullanılmıştır. Şekil 9 (a)'da PRN 4 numaralı GPS uydu izine ait SNR salınımları ve Şekil 9 (b)'de LSP sonuçları gösterilmiştir. Burada, kullanılan uydu yükseklik açısı ve azimut aralığında yeterli sayıda SNR verisi olmaması nedeniyle DATC istasyonuna ait SNR salınımları düzenli bir şekilde artmamaktadır. Sonuç olarak LSP analizinde de birden çok pik elde edilmiş olup zayıf yansıma sinyalleri mevcuttur. Bu nedenle DATC istasyonunda dominant frekans ve anlamlı reflektör yükseklikleri elde edilememiştir (Şekil 9 (b)). 

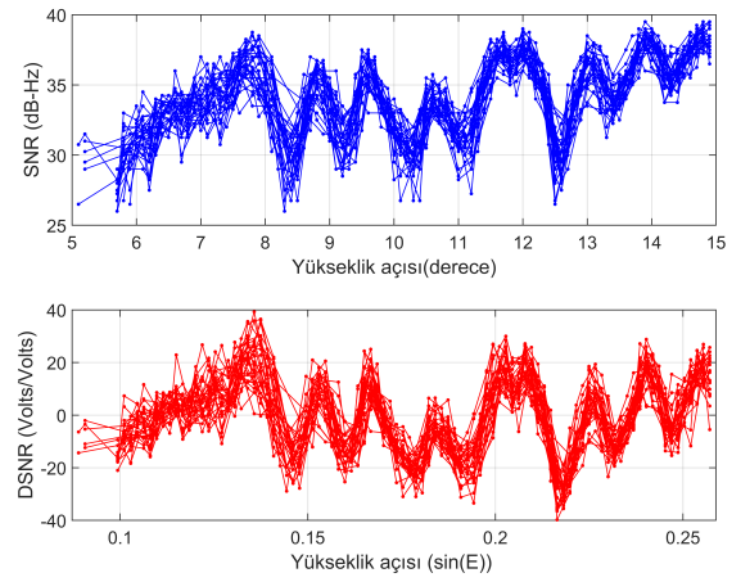

(a)

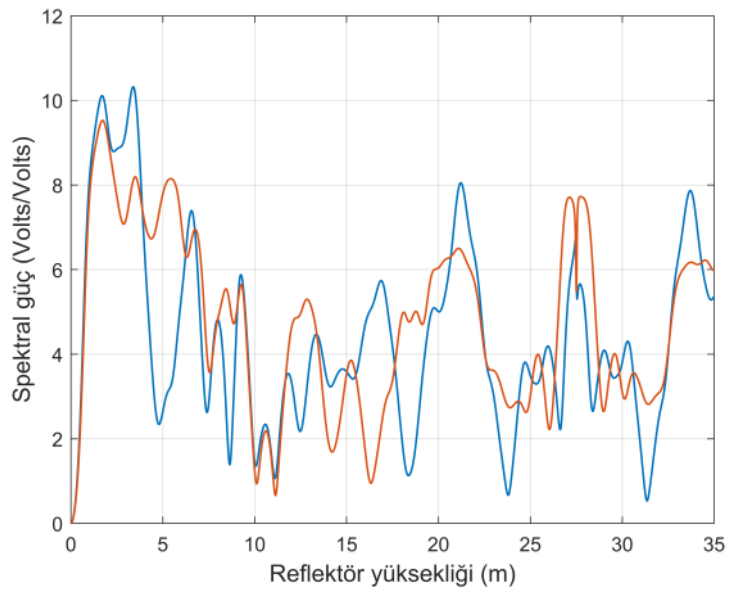

(b)

Şekil 9: (a) DATC istasyonunda ait SNR salıımları. Mavi renk doğrudan gelen ve yansıyan sinyali içeren SNR, kırmızı renk ise doğrudan gelen sinyalin etkisinden arındırılmış DSNR salınımlarını göstermektedir. (b) DATC istasyonuna ait doğrudan gelen sinyal etkisinin kaldırıldı̆ı SNR verileri kullanılarak DOY 122 ve DOY 123 için hesaplanan LSP salınımları

Karadeniz bölgesinde bulunan FASA istasyonuna ait $5^{\circ}-10^{\circ}$ uydu yükseklik açıS1 ve $60^{\circ}-100^{\circ}$ azimut aralığındaki uydu izlerine ait SNR verileri kullanılmıştır. FASA istasyonunda denizi kapsayan uydu izlerinin dar bir azimut aralığında olduğu görülmüştür. Bölgedeki diğer istasyonlara göre denize yakın olmasına rağmen $5^{\circ}$ den küçük uydu izlerinin olmaması nedeniyle denizi kapsayan çok az sayıda uydu izinin kullanılması ile SNR salınımlarının yeterli düzeyde olmadığı görülmüştür. Sonuç olarak zayıf yansıma genlikleri elde edilmiş olup dominant frekans hesaplanamamışıtır. Şekil 10 (a)'da PRN 20 numaralı GPS uydu izine ait SNR salınımları ve Şekil 10 (b)'de LSP sonuçları gösterilmiştir.
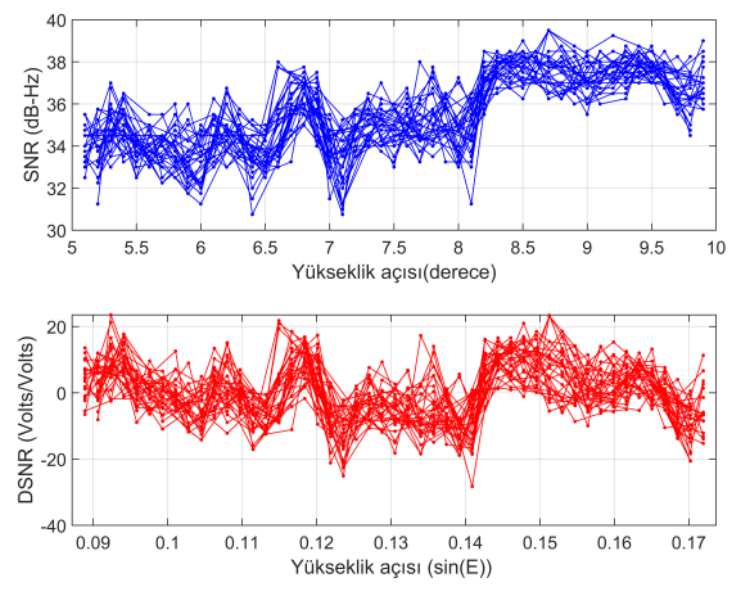

(a)

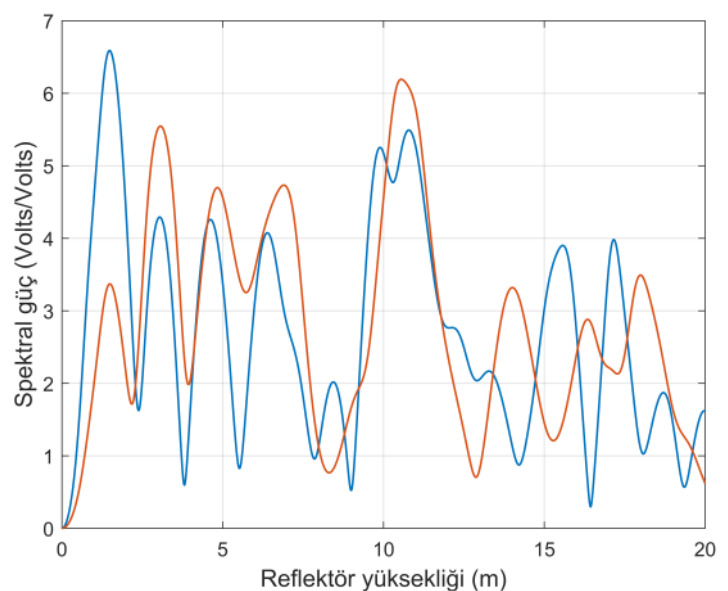

(b)

Şekil 10: (a) FASA istasyonunda ait SNR salınımları. Mavi renk doğrudan gelen ve yansıyan sinyali içeren SNR, kırmızı renk ise doğrudan gelen sinyalin etkisinden arındırılmış DSNR salınımlarını göstermektedir. (b) FASA istasyonuna ait doğrudan gelen sinyal etkisinin kaldırıldığı SNR verileri kullanılarak DOY 122 ve DOY 123 için hesaplanan LSP salınımları

Akdeniz bölgesinde bulunan MERS istasyonuna ait $5^{\circ}-20^{\circ}$ uydu yükseklik açısı ve $60^{\circ}-160^{\circ}$ azimut aralığındaki uydu izlerine ait SNR verileri kullanılmıştır. Şekil 11'de PRN 10 numaralı GPS uydu izine ait sonuçlar sunulmuştur. Şekil 11(a)'da SNR verilerinin $\sim 45 \mathrm{~dB}-\mathrm{Hz}$ seviyesine kadar düzgün olarak yükseldiği görülmüştür. LSP analizi sonucunda, Şekil 11(b)'de reflektör yüksekliklerinin aynı değer etrafında toplandığı görülmüştür. 

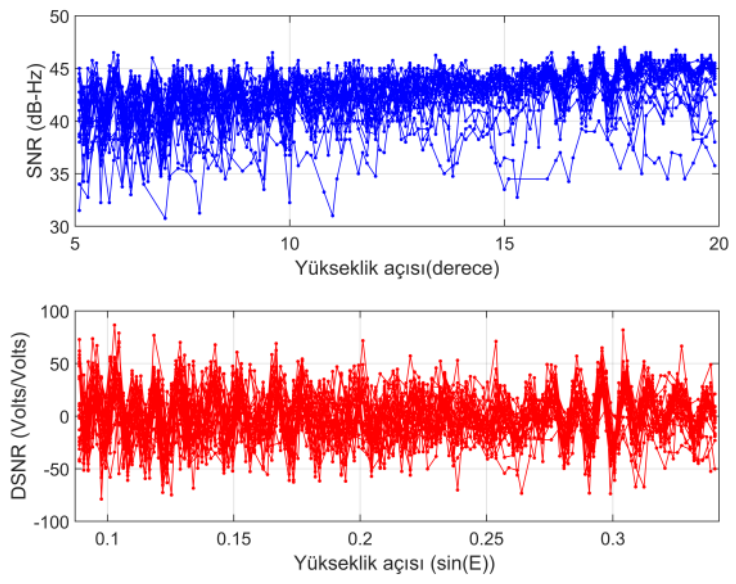

(a)

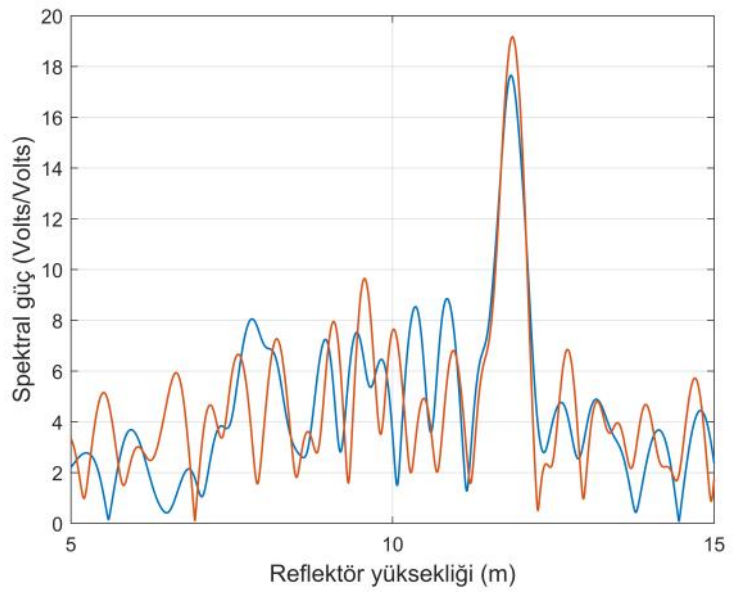

(b)

Şekil 11: (a) MERS istasyonunda ait SNR salınımları. Mavi renk doğrudan gelen ve yansıyan sinyali içeren SNR, kırmızı renk ise doğrudan gelen sinyalin etkisinden arındııımış DSNR salınımlarıı göstermektedir. (b) MERS istasyonuna ait doğrudan gelen sinyal etkisinin kaldırıldığ SNR verileri kullanılarak DOY 136 ve DOY 144 için hesaplanan LSP salınımları

MERS sabit GNSS istasyonunda GNSS-R ile hesaplanan deniz seviyesi verileri ile istasyon yakınında bulunan Erdemli mareograf istasyonu deniz seviyesi gözlemleri karşılaştırılmıştır (Şekil 12). Her iki zaman serisi arasındaki Pearson korelasyon katsayısı 0.76 olarak hesaplanmıştır.

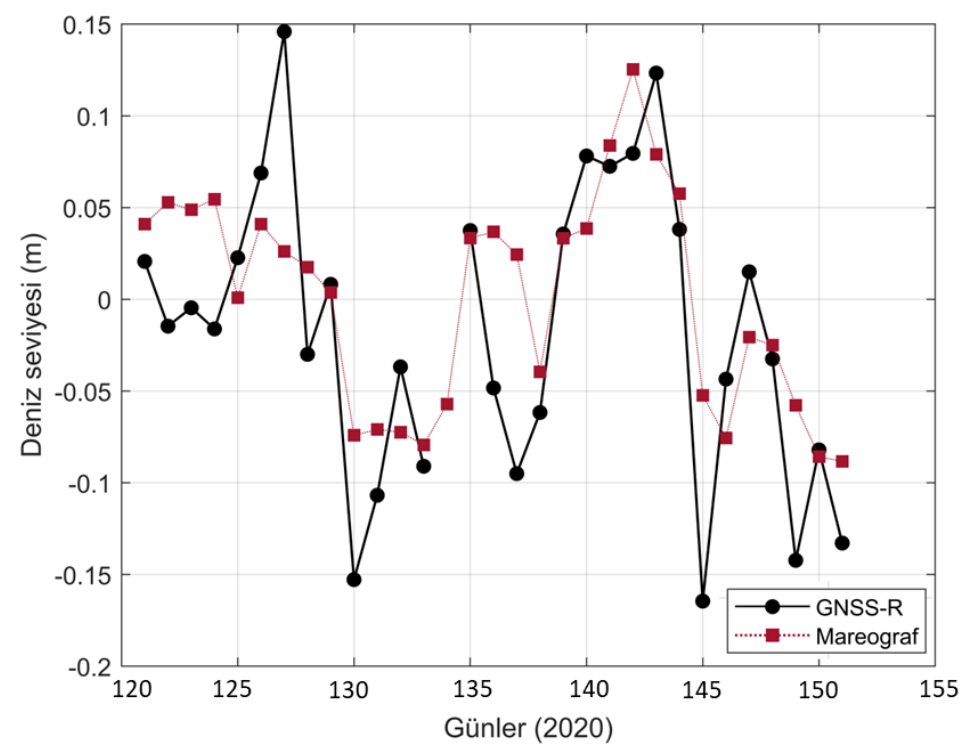

Şekil 12: MERS istasyonu GNSS-R ile tahmin edilen deniz seviyesi ve Erdemli mareograf istasyonu deniz seviyesi gözlemleri karşılaştırması

116Y186 nolu “Bölgesel GNSS Ağı ile Ekstrem Hava Olaylarının Tahmininin Güçlendirilmesi” başlıklı TÜBİTAK 1001 projesi kapsamında Karadeniz bölgesinde kurulmuş olan SAME istasyonunda GNSS-R yöntemiyle ile deniz seviyesi belirlenmesi amacıyla, $1^{\circ}-20^{\circ}$ uydu yükseklik açısı ve $0^{\circ}-90^{\circ}$ azimut aralığındaki uydu izlerine ait SNR verileri kullanılmıştır. Denizi kapsayan alandaki uydu izlerine ulaşmak için uydu yükseklik açılarında $1^{\circ}$ ye kadar inilmesi sonucu troposferik hatada artış meydana gelmiş olup düzgün SNR salınımları elde edilememiştir.

Karadeniz bölgesinde bulunan SINP istasyonuna ait $5^{\circ}-10^{\circ}$ uydu yükseklik açısı ve $300^{\circ}-330^{\circ}$ azimut aralığındaki uydu izlerine ait SNR verileri kullanılmıştır. Bu istasyonda da denizi kapsayan uydu izlerinin dar bir azimut aralığında olduğu 
görülmüştür. Bu nedenle yeterli sayıda uydu izine ulaşılamamış olup istenilen şekilde SNR salınımları elde edilememiştir. Şekil 13 (a)'da PRN 32 numaralı GPS uydu izine ait SNR salınımları ve Şekil 13 (b)'de LSP analizi sonuçları gösterilmiştir.
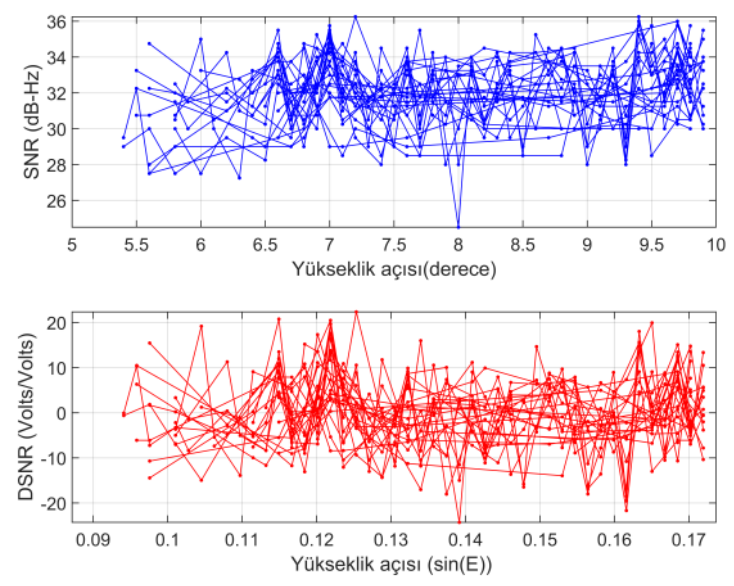

(a)

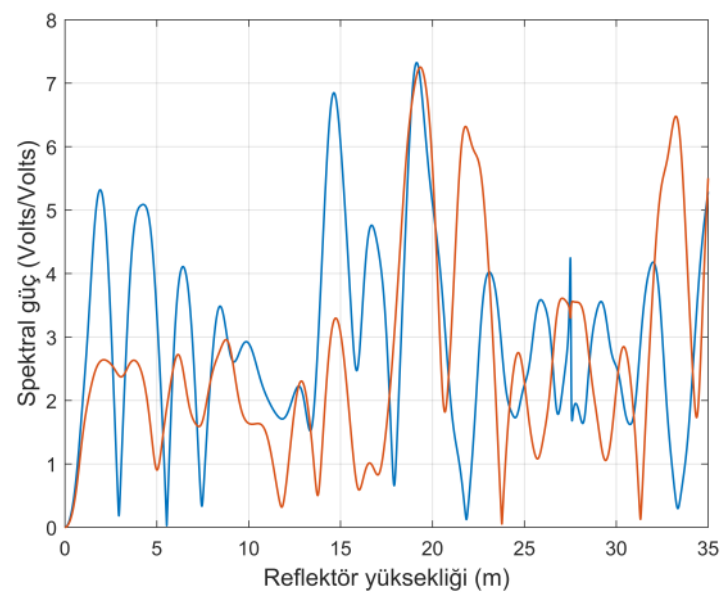

(b)

Şekil 13: (a) SINP istasyonunda ait SNR salınımları. Mavi renk doğrudan gelen ve yansıyan sinyali içeren SNR, kırmızı renk ise doğrudan gelen sinyalin etkisinden arındırılmış DSNR salınımlarını göstermektedir. (b) SINP istasyonuna ait doğrudan gelen sinyal etkisinin kaldırıldığı SNR verileri kullanılarak DOY 122 ve DOY 123 için hesaplanan LSP salınımları

Marmara bölgesinde bulunan TEKR istasyonunda SNR salınımlarının daha net görüldüğü $5^{\circ}-20^{\circ}$ arasındaki uydu yükseklik açısına sahip uydu izleri kullanılmıştır. Azimut aralığı olarak $60^{\circ}-180^{\circ}$ seçilmiştir. Şekil 14 (a)'da PRN 32 numaralı GPS uydu izine ait SNR salınımları ve Şekil 14 (b)'de LSP analizi sonuçları gösterilmiştir. SNR salınımlarının $\sim 30-43 \mathrm{~dB}-\mathrm{Hz}$ arasında değiştiği görülmüştür. Reflektör yüksekliklerini hesaplamak için yapılan LSP sonucunda her bir salınımın aynı değer etrafinda pik yaptığg görülmüştür.

TEKR sabit GNSS istasyonunda GNSS-R ile hesaplanan deniz seviyesi verileri ile istasyona en yakın Marmara Ereğlisi mareograf istasyonu deniz seviyesi gözlemleri ile karşılaştırılmıştır (Şekil 15). Her iki zaman serisi arasındaki Pearson korelasyon katsayısı 0.91 olarak hesaplanmıştır.
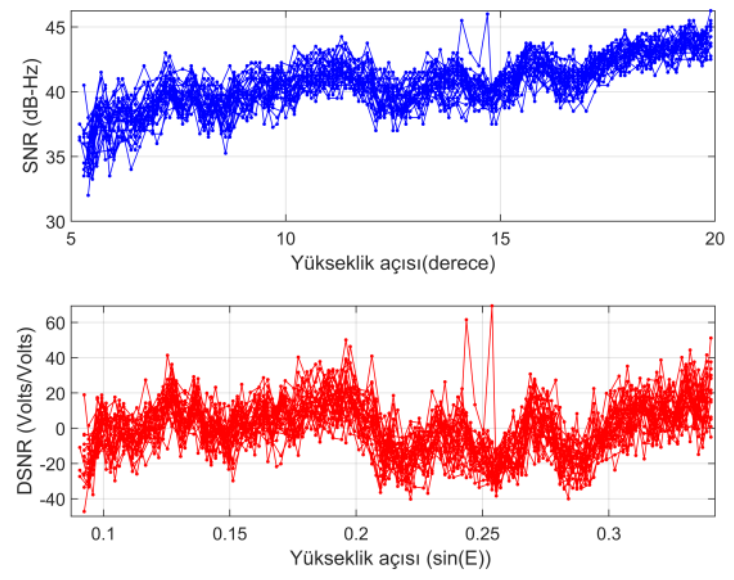

(a)

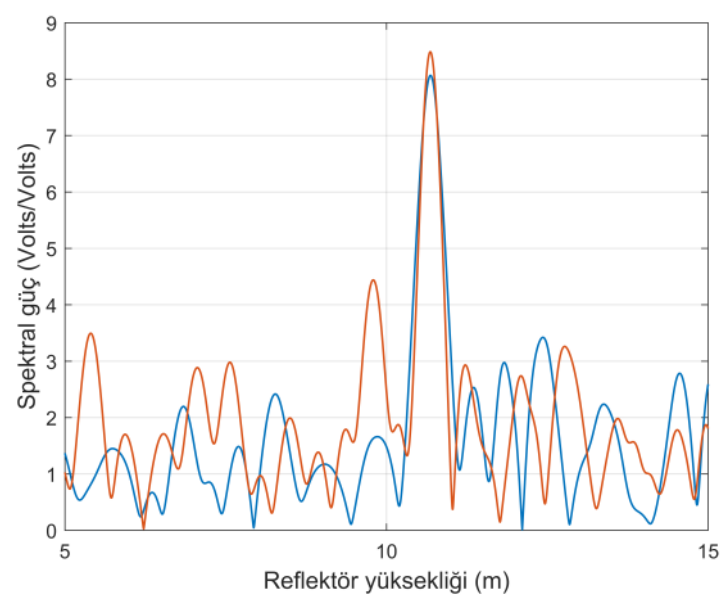

(b)

Şekil 14: (a) TEKR istasyonunda ait SNR salınımları. Mavi renk doğrudan gelen ve yansıyan sinyali içeren SNR, kırmızı renk ise doğrudan gelen sinyalin etkisinden arındırılmış DSNR salınımlarını göstermektedir. (b) TEKR istasyonuna ait doğrudan gelen sinyal etkisinin kaldırılı̆̆ı SNR verileri kullanılarak DOY 122 ve DOY 140 için hesaplanan LSP salınımları 


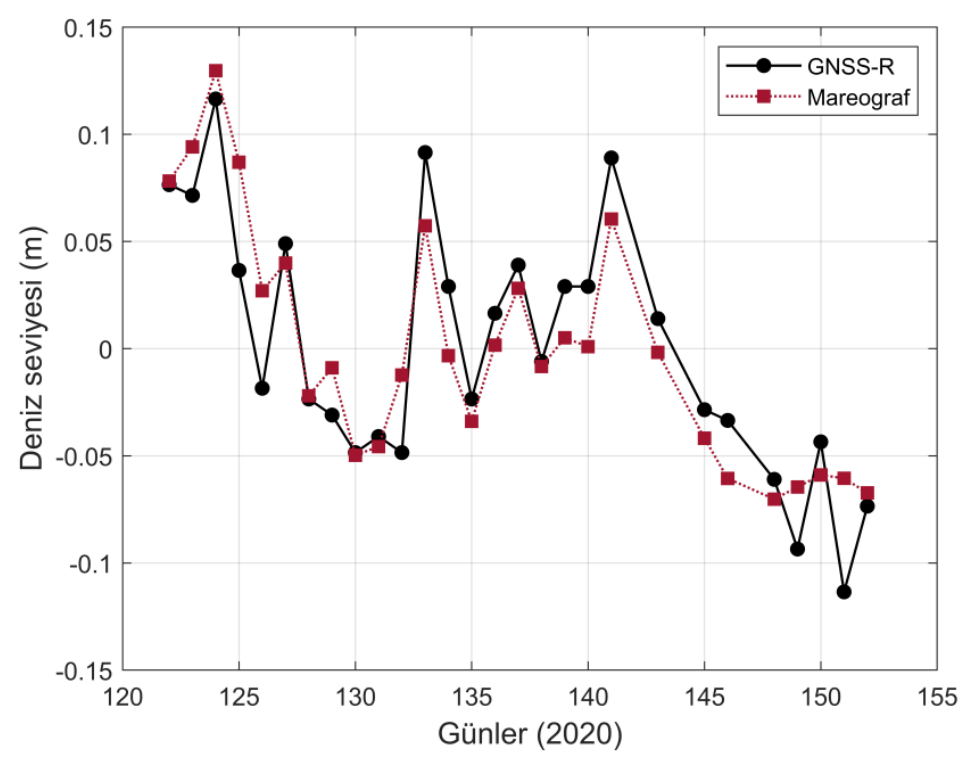

Şekil 15: TEKR istasyonu GNSS-R ile tahmin edilen deniz seviyesi ve Marmara Ereğlisi mareograf istasyonu deniz seviyesi gözlemleri karşılaştırması

\section{Sonuçlar}

İklim değişikliği senaryolarında önemli bir parametre olan deniz seviyesi değişiminin izlenmesinde hem bölgesel hem de küresel etkilerin bilinmesi ve bu etkilerin değerlendirilmesi önemlidir. GNSS-R uzaktan algılanabilir bir tekniktir ve ekonomik olarak avantajlıdır. Gelgit etkilerini mareograf istasyonlarına kıyasla daha doğru belirleyebilmektedir. Bir diğer avantajı ise Uluslararası Yersel Referans Ağı'na (ITRF) göre deniz seviyesinin ölçülmesine yani mutlak deniz seviyesi bilgisine olanak sağlamasıdır.

Çalışma kapsamında Türkiye kıyılarında bulunan MERS IGS istasyonu ve ANMU, DATC, FASA, SINP ve TEKR TUSAGA-Aktif istasyonu,116Y186 kodlu TÜBİTAK projesi kapsamında Samsun'da kıyıya yakın bir alanda tesis edilmiş SAME GNSS istasyonlarında kaydedilmiş veriler kullanılarak, GNSS-R tekniği ile istasyonların bulunduğu kıyılarda deniz seviyesi belirlemesi yapılmıştır. Aynı zamanda ülkemizin farklı kıyılarında IGS, TUSAGA-Aktif ve özel amaçlı tesis edilmiş sabit GNSS istasyonlarının GNSS-R yöntemi ile deniz seviyesi belirlenmesine uygun olup olmadığı belirlenmeye çalışılmıştır. Çalışma kapsamında kullanılan toplam 7 istasyonun sadece 2'si GNSS-R tekniği ile deniz seviyesi belirlemeye elverişli durumda veri sağladığı tespit edilmiştir.

Akdeniz'de MERS ve Marmara denizinde TEKR istasyonları uygun istasyonlar olarak bulunmuştur. MERS sabit GNSS istasyonundan tahmin edilen GNSS tabanlı deniz seviyesi, istasyona yakın Erdemli mareograf gözlemleri ile karşılaştırılmıştır. İki gözlem verisi arasındaki Pearson korelasyonu 0.76 olarak hesaplanmıştır. TEKR sabit GNSS istasyonu ise yine istasyona yakın Marmara Ereğlisi mareograf gözlemleri ile karşılaştırıldığında, iki gözlem verisi arasındaki Pearson korelasyonu 0.91 olarak elde edilmiştir. Deniz seviyesinden yüksekliği düşük olan ANMU ve FASA istasyonlarında belirlenen azimut ve uydu yükseklik açılarında uygun uydu izleri olmaması nedeniyle deniz seviyesi belirlenememiştir. İstasyonun bulunduğu yerdeki bina, dağ ve kayalık gibi çevresel koşullarda bu sonucu etkileyen faktörler olarak değerlendirilmektedir. Aynı zamanda ANMU, DATC, FASA ve SINP TUSAGA-Aktif istasyonlarında denizi kapsayan alanlardaki uydu izlerine ulaşmak için dar yükseklik açısı maskesi yapılmak zorunda kalınmış ve bu istasyonlarda sınırlı sayıda ve açık olmayan SNR salınımları elde edilmiş̧ir. GNSS-R tekniğinin avantajlarının yanında tekniğin doğruluğunu arttırmak için daha fazla gelişmeye de ihtiyaç vardır. Çok düşük yükseklik açılarında SNR frekansındaki değişim çoğunlukla 
GNSS radyo dalgalarındaki troposfer kaynaklı kırılma ile ilişkilendirilmektedir. Bu etki lokal atmosferik sıcaklık ve basınç gözlemleri kullanılarak büyük çoğunlukla düzeltilmektedir. Elde edilen sonuçların kalitesinin farklı kalite kontrollerinin de çalışmaya dahil edilmesi, istasyonlar için daha kısa veri kayıt aralıklarının sağlanması ile yükseltilmesi mümkündür.

GNSS istasyonlarının jeodezik amaçlı kullanımının yanı sıra jeodinamik aktivitelerin araştırılması ve meteorolojik tahminleri güçlendirilmesi amacıyla ürünler sağladığı hem ülkemizde hem de dünyada yapılan çeşitli araştırmalarda bilinmektedir. Son dönemlerde dünyada yapılan çeşitli çalışmalarda GNSS-R tekniği ile GNSS istasyonlarının deniz seviyesi değişimlerinin araştırılmasına da önemli katkılar sağladığı görülmektedir. Bu anlamda GNSS-R tekniğinin ülkemizde deniz seviyesi izlemede önemli bir potansiyel olabileceği gerçeği ile kıyılarda mevcut GNSS istasyonlarımızın GNSS-R tekniği ile deniz seviyesi belirlemeye uygun özellikle veri temin edebilmesi ve hatta uygun alanlara yeni GNSS istasyonlarının tesis edilmesi konusunda çalışmaların teşvik edilmesinin önemli olduğu düşünülmektedir.

\section{Teşekkür}

Çalışmada kullanılan TUSAGA-Aktif GNSS verilerini (https://www.tusaga-aktif.gov.tr/) linki üzerinden sağlayan Tapu ve Kadastro Genel Müdürlüğü ile Harita Genel Müdürlüğüne, TUDES verilerini (https://tudes.harita.gov.tr/) linki üzerinden sağlayan Harita Genel Müdürlüğüne ve IGS istasyon verilerini (https://www.unavco.org/) linki üzerinden UNAVCO’a teşekkür ederiz.

\section{Yazar Katkısı}

Cansu Beşel: Fikir, Tasarım, Literatür Taraması, Veri Toplama ve İşleme, Analiz ve Yorumlama, Yazım. Emine Tanır Kayıkçı: Fikir, Yazım, Denetleme, Makale değerlendirme.

\section{Kaynaklar}

Cazenave, A., Dieng, H. B., Meyssignac, B., von Schuckmann, K., Decharme, B., \& Berthier, E. (2014). The rate of sea-level rise. Nature Climate Change, 4(5), 358-361.

Chelton, D., Ries, J., Haines, B., Fu, L., \& Callahan, P. (2001). Satellite Altimetry, Satellite Altimetry and Earth Sciences: A Handbook for Techniques and Applications, L.L. Fu ve A. Cazenave.

IPCC (2007). Climate Change 2007: Synthesis Report. Contribution of Working Groups I, II and III to the Fourth Assessment Report of the Intergovernmental Panel on Climate Change, IPCC, İsviçre.

IPCC (2013). Sea Level Change. In: Climate Change 2013: The Physical Science Basis. Contribution of Working Group I to the Fifth Assessment Report of the Intergovernmental Panel on Climate Change, Cambridge University Press, Cambridge, Birleşik Krallık ve New York.

Joseph, A. (2010). What is the difference between SNR and C/N0. InsideGNSS, 5(8), 20-25.

Larson, K. M., Small, E. E., Gutmann, E., Bilich, A., Axelrad, P., \& Braun, J. (2008). Using GPS multipath to measure soil moisture fluctuations: initial results. GPS solutions, 12(3), 173-177.

Larson, K. M., Löfgren, J. S., \& Haas, R. (2013a). Coastal sea level measurements using a single geodetic GPS receiver. Advances in Space Research, 51(8), 1301-1310.

Larson, K. M., Ray, R. D., Nievinski, F. G., \& Freymueller, J. T. (2013b). The accidental tide gauge: a GPS reflection case study from Kachemak Bay, Alaska. IEEE Geoscience and Remote Sensing Letters, 10(5), 1200-1204.

Larson, K. M., \& Nievinski, F. G. (2013). GPS snow sensing: results from the EarthScope Plate Boundary Observatory. GPS solutions, 17(1), 41-52. 
Larson, K.M., Ray, R.D. \& Williams, S.D.P. (2017). A 10-year comparison of water levels measured with a geodetic GPS receiver versus a conventional tide gauge. Journal of Atmospheric and Oceanic Technology, 34: 295-307.

Lee, C. M., Kuo, C. Y., Sun, J., Tseng, T. P., Chen, K. H., Lan, W. H., Shum, C. K., Ali, T., Ching, K. E., Chu, P. \& Jia, Y. (2019). Evaluation and improvement of coastal GNSS reflectometry sea level variations from existing GNSS stations in Taiwan. Advances in Space Research, 63(3), 1280-1288.

Li , F. (2018). Sea Surface Altimetry using GNSS-R (Lisans tezi). Universität Stuttgart, Geodäsie und Geoinformatik, Stuttgart, Almanya.

Löfgren, J. S., Haas, R., \& Johansson, J. M. (2010). High-rate local sea level monitoring with a GNSS-based tide gauge. 2010 IEEE International Geoscience and Remote Sensing Symposium, 3616-3619.

Löfgren, J. S., Haas, R., \& Scherneck, H. G. (2011). Sea-Level analysis using 100 days of reflected GNSS signals. Proceedings of the 3rd International Colloquium-Scientific and Fundamental Aspects of the Galileo Programme, Copenhagen, Denmark (No. WPP 326).

Löfgren J. S. (2014). Local sea level observations using reflected GNSS signals (Doktora Tezi). Chalmers University of Technology, Department of Earth and Space Sciences, Gothenburg, İsveç.

Löfgren, J. S., Haas, R., \& Scherneck, H. G. (2014). Sea level time series and ocean tide analysis from multipath signals at five GPS sites in different parts of the world. Journal of Geodynamics, 80, 66-80.

Martin-Neira, M. (1993). A passive reflectometry and interferometry system (PARIS): Application to ocean altimetry. ESA journal, 17(4), 331-355.

Roesler, C., \& Larson, K. M. (2018). Software tools for GNSS interferometric reflectometry (GNSS-IR). GPS Solutions, 22 (3), 80.

Santamaría-Gómez, A., Watson, C., Gravelle, M., King, M., \& Wöppelmann, G. (2015). Levelling co-located GNSS and tide gauge stations using GNSS reflectometry. Journal of Geodesy, 89(3), 241-258.

Santamaría-Gómez, A., \& Watson, C. (2017). Remote leveling of tide gauges using GNSS reflectometry: case study at Spring Bay, Australia. GPS solutions, 21(2), 451-459.

Selbesoğlu, M. O., Yavaşoğlu, H. H., Karabulut, M. F., Gülal, V. E., Karaman, H., \& Kamaşak, M. E.(2019). Monitoring the water vapor, snow/ice and sea level changes in the Antarctica with GNSS Meteorology and GNSS Reflectometry Techniques. XXIX International Symposium On: “Modern Technologies, Education And Professional Practice In Geodesy And Related Fields”, 21.

Simav, M. (2012). Uydu ve model verilerine dayalı Akdeniz su kütlesi değişimleri (Doktora Tezi). İstanbul Teknik Üniversitesi, Fen Bilimleri Enstitüsü, İstanbul.

Tunalığlu, N., Doğan, A. H., \& Durdağ, U. M. (2019). GPS sinyal gürültü oranı verileri ile kar kalınlığının belirlenmesi. Jeodezi ve Jeoinformasyon Dergisi, 6(1),1-9.

Tüysüz, N. \& Yaylalı Abanuz, G. (2012). Jeoistatistik: Kavramlar ve Bilgisayarlı Uygulamalar, s. 171, KTÜ Matbaası, Trabzon, Türkiye.

Vey, S., Güntner, A., Wickert, J., Blume, T., \& Ramatschi, M. (2016). Long-term soil moisture dynamics derived from GNSS interferometric reflectometry: a case study for Sutherland, South Africa. GPS solutions, 20(4), 641-654.

Wan, W., Larson, K. M., Small, E. E., Chew, C. C., \& Braun, J. J. (2015). Using geodetic GPS receivers to measure vegetation water content. GPS Solutions, 19(2), 237-248.

URL-1: https://www.star.nesdis.noaa.gov/socd/lsa/SeaLevelRise, (Erişim Tarihi : 31 Ağustos 2020).

URL-2: https://www.unavco.org/data/gps-gnss/data-access-methods/dai2/app/dai2.html, (Erişim Tarihi : 14 Şubat 2020).

URL-3: https://www.tusaga-aktif.gov.tr/, (Erişim Tarihi : 8 Haziran 2020).

URL-4: https://tudes.harita.gov.tr/, (Erişim Tarihi : 8 Haziran 2020). 